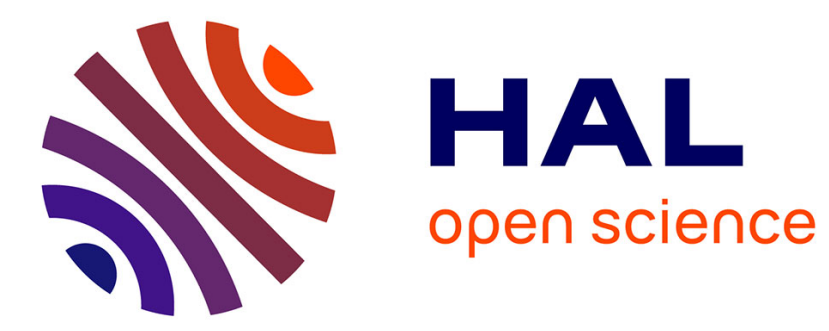

\title{
Filtering over networks with random communication
}

Aneel Tanwani

\section{To cite this version:}

Aneel Tanwani. Filtering over networks with random communication. HSCC '21: 24th ACM International Conference on Hybrid Systems: Computation and Control, May 2021, Nashville (virtual), United States. pp.1-2, 10.1145/3447928.3457212 . hal-03217508

\section{HAL Id: hal-03217508 \\ https://hal.science/hal-03217508}

Submitted on 4 May 2021

HAL is a multi-disciplinary open access archive for the deposit and dissemination of scientific research documents, whether they are published or not. The documents may come from teaching and research institutions in France or abroad, or from public or private research centers.
L'archive ouverte pluridisciplinaire HAL, est destinée au dépôt et à la diffusion de documents scientifiques de niveau recherche, publiés ou non, émanant des établissements d'enseignement et de recherche français ou étrangers, des laboratoires publics ou privés. 
archives-ouvertes

\title{
Filtering over networks with random communication
}

\author{
Aneel Tanwani
}

\section{To cite this version:}

Aneel Tanwani. Filtering over networks with random communication. HSCC '21: 24th ACM International Conference on Hybrid Systems: Computation and Control, May 2021, Nashville Tennessee, United States. pp.1-2, 10.1145/3447928.3457212 . hal-03217508

\section{HAL Id: hal-03217508 \\ https://hal.archives-ouvertes.fr/hal-03217508}

Submitted on 4 May 2021

HAL is a multi-disciplinary open access archive for the deposit and dissemination of scientific research documents, whether they are published or not. The documents may come from teaching and research institutions in France or abroad, or from public or private research centers.
L'archive ouverte pluridisciplinaire HAL, est destinée au dépôt et à la diffusion de documents scientifiques de niveau recherche, publiés ou non, émanant des établissements d'enseignement et de recherche français ou étrangers, des laboratoires publics ou privés. 


\title{
Poster: Filtering over Networks with Random Communication
}

\author{
Aneel Tanwani \\ LAAS - CNRS, 7 Avenue du Colonel Roche, 31400 Toulouse, France \\ aneel.tanwani@laas.fr
}

\begin{abstract}
We consider analysis and design of distributed filters for continuoustime stochastic systems, where the partial information about the states is measured by a distributed set of sensor units. These units are represented by nodes in an undirected and connected graph, whose edges represent the communication links between sensor units. It is stipulated that the communication between sensor nodes is time-sampled randomly and the sampling process is described by a Poisson counter. Our proposed filtering algorithm for each sensor node is a stochastic hybrid system: It comprises a continuous-time differential equation, and at random time instants when communication takes place, each sensor node updates its state estimate based on the information received by its neighbors. For this setup, we compute the expectation of the error covariance matrix for each node which is governed by a matrix differential equation, and relate its convergence with the mean sampling rate.
\end{abstract}

\section{CCS CONCEPTS}

- Mathematics of computing $\rightarrow$ Mathematical analysis; • Networks $\rightarrow$ Network algorithms; • Computing methodologies $\rightarrow$ Distributed algorithms.

\section{KEYWORDS}

Distributed filtering, Random sampling, Stochastic hybrid system

\section{ACM Reference Format:}

Aneel Tanwani. 2021. Poster: Filtering over Networks with Random Communication. In 24th ACM International Conference on Hybrid Systems: Computation and Control (HSCC '21), May 19-21, 2021, Nashville, TN, USA. ACM, New York, NY, USA, 2 pages. https://doi.org/10.1145/3447928.3457212

\section{INTRODUCTION}

Modern engineering systems often involve integration of several components, due to which it becomes difficult to monitor all the output measurements of the system in a single processing unit. This has led to the increasing research in the area of distributed algorithms, and in particular for state estimation, and filtering, in dynamical systems. Distributed filtering allows us to disintegrate a centralized output into several components, and then associate a filtering algorithm with each of these smaller components, see Figure 1 for a conventional layout of such architectures. In the usual operation of distributed filters, it is assumed that the sensor units, represented by the nodes in a graph, communicate the information about their own estimate to their neighbors (determined by the graph topology) at all times. In our work, however, we put constraints on the communication between these dynamic agents, which represent the individual filtering units. In particular, we assume that each link in the graph is activated at random time-instants and the random process, which determines the discrete-times at which two neighbors communicate, is described by a Poisson counter. For this problem setup, we propose filtering algorithm in the form of a stochastic hybrid system. Such framework has been advocated in [1] for control problems over networks with communication constraints. Some historical developments on the use of Poisson counters for sampling process are provided in [4]. The results proposed in this work build on the centralized filtering case studied in [5]. Our analysis of the asymptotic behavior of the error covariances borrows tools from the stability of networked systems with heterogenous agents [2].

\section{PROBLEM SETUP}

We consider the dynamical system

$$
\mathrm{d} x=A x \mathrm{~d} t+B \mathrm{~d} \omega
$$

where $(x(t))_{t \geqslant 0}$ is an $\mathbb{R}^{n}$-valued diffusion process describing the state. It is assumed that, for each $t \geqslant 0,(\omega(t))_{t \geqslant 0}$ is an $\mathbb{R}^{m}$-valued standard Wiener process with the property that $\mathrm{E}\left[\mathrm{d} \omega(t) \mathrm{d} \omega(t)^{\top}\right]=$ $I_{m \times m}$, for each $t \geqslant 0$. The matrices $A \in \mathbb{R}^{n \times n}$ and $B \in \mathbb{R}^{n \times m}$ are taken as constant, and the process $(\omega(t))_{t \geqslant 0}$ does not depend on the state. The solutions of the stochastic differential equation (1) are interpreted in the sense of Itô stochastic integral.

Measurements via distributed sensors. The measurements associated with system (1) are obtained from a set of $N$ sensors which are

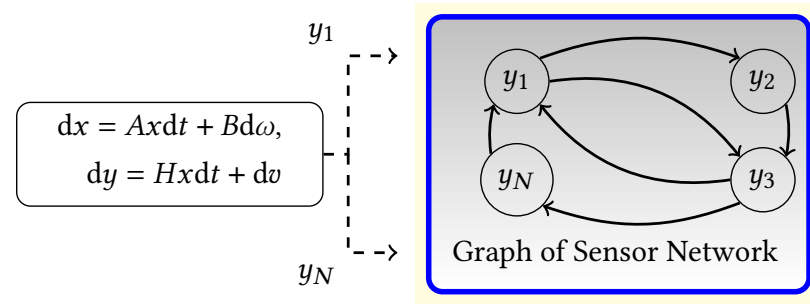

Figure 1: Layout of Distributed Filters 
distributed in their localization. Each of these sensors provides a partial measurement about the state described as,

$$
\mathrm{d} y_{i}=H_{i} x \mathrm{~d} t+\mathrm{d} v_{i}, \quad i=1, \ldots, N,
$$

with $H_{i} \in \mathbb{R}^{p_{i} \times n}$, and we let $\sum_{i=1}^{N} p_{i}=: p$. That is, for each node, $\left(y_{i}(t)\right)_{t \geqslant 0}$ describes an $\mathbb{R}^{p_{i}}$-valued continuous-time observation process. In the observation equation (2), $v_{i}$ is a standard Wiener process, taking values in $\mathbb{R}^{p_{i}}$, and $\mathrm{E}\left[\mathrm{d} v_{i}(t) \mathrm{d} v_{i}(t)^{\top}\right]=V_{i} \in \mathbb{R}^{p_{i} \times p_{i}}$, for each $t \geqslant 0$, with $V_{i}$ assumed to be positive definite.

Communication Process. The sensor nodes are connected via a graph $\mathcal{G}=(\mathcal{V}, \mathcal{E})$, where $\mathcal{V}=\{1, \ldots, N\}$ is the set of graph nodes, and $\mathcal{E}$ contains all the edges defined by the pairs $(i, j), i \neq j, i, j \in \mathcal{V}$. We assume that the graph is undirected and connected. The neighbors of a node $i \in \mathcal{V}$ are denoted by $\mathcal{N}_{i}:=\{j \in \mathcal{V} \mid(i, j) \in \mathcal{E}\}$, and we adopt the convention that $i \notin \mathcal{N}_{i}$. It is assumed that there exists a monotone strictly increasing and divergent sequence $\left(\tau_{k}\right)_{k \in \mathbb{N}} \subset$ $\left[0,+\infty\left[\right.\right.$ with $\tau_{0}:=0$, and

- at each time instant $\tau_{k}$, all sensor nodes $i \in \mathcal{V}$ transmit the value of their state estimate to their neighbors $\mathcal{N}_{i}$.

In this note, we are interested in the case where the sampling times $\left(\tau_{k}\right)_{k \in \mathbb{N}}$ are generated randomly. Formally, we define

$$
N_{t}:=\sup \left\{k \in \mathbb{N} \mid \tau_{k} \leqslant t\right\} \quad \text { for } t \geqslant 0
$$

and stipulate in addition that

- $\left(N_{t}\right)_{t \geqslant 0}$ is a Poisson process of intensity $\lambda>0$ satisfying $\tau_{N_{t}} \underset{t \uparrow+\infty}{\longrightarrow}+\infty$ almost surely.

The map $t \mapsto N_{t}$ increments by 1 at random times, and it provides a description of the number of samples up to and including time $t$.

\section{ALGORITHM AND MAIN RESULT}

Filtering Algorithm. Based on the aforementioned communication architecture, we propose the following algorithm to be implemented by each sensor node:

$$
\mathrm{d} \widehat{x}_{i}(t)=\left(A-L_{i} H_{i}\right) \widehat{x}_{i}(t) \mathrm{d} t+L_{i} \mathrm{~d} y_{i}(t)
$$

over the intervals $\left[\tau_{N_{t}}, \tau_{N_{t}+1}\right.$ [, with $L_{i}$ being some constant matrix. At sampling times, when the sensor node $i \in \mathcal{V}$ receives the information from its neighbors, we update the estimate as follows:

$$
\begin{aligned}
\widehat{x}_{i}\left(\tau_{N_{t}}^{+}\right) & =\widehat{x}_{i}\left(\tau_{N_{t}}^{-}\right)+\epsilon \sum_{j \in \mathcal{N}_{i}}\left(\widehat{x}_{j}\left(\tau_{N_{t}}^{-}\right)-\widehat{x}_{i}\left(\tau_{N_{t}}^{-}\right)\right) \\
& =\pi_{i i} \widehat{x}_{i}\left(\tau_{N_{t}}^{-}\right)+\sum_{j \in \mathcal{N}_{i}} \pi_{i j} \widehat{x}_{j}\left(\tau_{N_{t}}^{-}\right),
\end{aligned}
$$

where $\pi_{i j} \in[0,1]$ is the $(i, j)$-th element of the symmetric doubly stochastic matrix $\Pi:=I_{N \times N}-\epsilon \mathcal{L}$, with $\mathcal{L}$ being the Laplacian of the communication graph $\mathcal{G}$, and $0<\epsilon \leqslant \min _{i \in \mathcal{V}} \frac{1}{\left|\mathcal{N}_{i}\right|}$. Each of these filters is a stochastic hybrid system with continuous evolution described by (3) between sampling times, and the jump rule (4) executed at random sampling instants where we update the estimate $\widehat{x}_{i}$ as the convex combination of itself and its neighbors. The communication based on the underlying graph results in a particular interconnection of these hybrid systems.

To state our main result concerning the performance bounds of the filters (3)-(4), we let $\mathcal{Y}_{t}^{i}:=\left\{\left(\mathrm{d} y_{i}(s), \widehat{x}_{j}\left(\tau_{N_{s}}\right)\right) \mid s \leqslant t, j \in \mathcal{N}_{i}\right\}$ denote the information available to node $i \in \mathcal{V}$ up to time $t$, and introduce two matrices $L \in \mathbb{R}^{n \times p}$ and $H \in \mathbb{R}^{p \times n}$ as follows:

$$
L:=\frac{1}{N}\left[\begin{array}{lll}
L_{1} \mid & \ldots & \mid L_{N}
\end{array}\right], \quad H:=\left[\begin{array}{llll}
H_{1}^{\top} \mid & \ldots & H_{N}^{\top}
\end{array}\right]^{\top} .
$$

Consequently, we see that $A-L H=A-\frac{1}{N} \sum_{i=1}^{n} L_{i} H_{i}$. The result providing bounds on error covariance matrices appears below and its proof can be found in [3].

Theorem 3.1. Consider system (1) with distributed measurements (2). Suppose that the corresponding hybrid filters (3), (4) represent the nodes of a directed and connected graph, where the communication between neighbors takes place at random times generated by a Poisson process of intensity $\lambda>0$. Then, the following items hold:

(1) For each $\lambda>0$, and $i=1, \ldots, N$, it holds that

$$
\mathrm{E}\left[\left(x(t)-\widehat{x}_{i}(t)\right)\left(x(t)-\widehat{x}_{i}(t)\right)^{\top} \mid \mathcal{y}_{t}^{i}\right] \leqslant \mathcal{P}_{i}(t),
$$

where the matrix-valued function $\mathcal{P}_{i}:\left[0, \infty\left[\rightarrow \mathbb{R}^{n \times n}\right.\right.$ satisfies the differential equation

$$
\begin{aligned}
\dot{\mathcal{P}}_{i}=\left(A-L_{i} H_{i}\right) \mathcal{P}_{i}+\mathcal{P}_{i}\left(A-L_{i} H_{i}\right)^{\top} & +B B^{\top}+L_{i} V_{i} L_{i}^{\top} \\
& +\lambda \sum_{j \in \mathcal{N}_{i}} \pi_{i j}\left(\mathcal{P}_{j}-\mathcal{P}_{i}\right)
\end{aligned}
$$

(2) If the gains $L_{i}$ are chosen such that the matrix $(A-L H)$ is Hurwitz, then for every $\varepsilon>0$, there exists $\lambda>0$ sufficiently large, such that the corresponding solution of (7) satisfies

$$
\limsup _{t \rightarrow \infty}\left\|\mathcal{P}_{i}(t)-S\right\| \leqslant \varepsilon,
$$

where $S$ is the symmetric positive semidefinite matrix satisfying

$$
0=(A-L H) S+S(A-L H)^{\top}+B B^{\top}+\frac{1}{N} \sum_{i=1}^{N} L_{i} V_{i} L_{i}^{\top} .
$$

\section{PERSPECTIVES}

Several research directions emerging from the result in Theorem 3.1 are being investigated. First one is the possibility of replacing the static gains in filtering equation (3) of each sensor node with optimal gains. Minimizing the mean square estimation error makes the injection gains dependent on the covariance matrix, which brings nonlinearity in (7) and this needs to be analyzed carefully. The second immediate concern is to consider a wider class of random processes for communication between individual sensor nodes.

\section{REFERENCES}

[1] J. P. Hespanha. 2014. Modeling and analysis of networked control systems using stochastic hybrid systems. Annual Reviews in Control 38, 2 (2014), 155 - 170.

[2] J. Kim, J. Yang, H. Shim, J.-S. Kim, and J.H. Seo. 2016. Robustness of synchronization of heterogeneous agents by strong coupling and a large number of agents. IEEE Trans. Automat. Control 61, 10 (2016), 3096-3102.

[3] A. Tanwani. 2021. Suboptimal filtering over sensor networks with random communication. (2021). Submitted for publication. Available online: https://hal.archivesouvertes.fr/hal-03106998.

[4] A. Tanwani, D. Chatterjee, and D. Liberzon. 2018. Stabilization of continuous-time deterministic systems under random sampling: Overview and recent developments. In Uncertainty in Complex Networked Systems, T. Başar (Ed.). Springer Nature, Switzerland, 209-246.

[5] A. Tanwani and O. Yufereva. 2020. Error covariance bounds for suboptimal filters with Lipschitzian drift and Poisson-sampled measurements. Automatica $122(2020)$. 